\title{
ANÁLISE DE OPORTUNIDADE DE NEGÓCIOS: ESTUDO DE CASO DA IMPLANTAÇÃO DO PROGRAMA MANDALA NA ESCOLA AGRÍCOLA MUNICIPAL ULISSES GUIMARÃES EM TANGARÁ DA SERRA-MT.
}

\author{
Kallypa Lara Scherwinski ${ }^{1}$ \\ Aparecida de Fátima Alves Lima
}

\section{RESUMO}

Diante das dificuldades enfrentadas pelos pequenos agricultores em sobreviver no mercado com a venda de seus produtos, surgem várias alternativas para sustentabilidade e geração de renda para as famílias. Esse artigo procura discutir se o programa Mandala adaptado pelos técnicos da Secretaria Municipal de Agricultura Pecuária e Abastecimento (SEAPA) pode ser considerado uma alternativa viável de empreendimento produtivo para os produtores familiares do município. Para tanto foram inicialmente, identificados os custos do investimento inicial e de produção, tendo em vista os requisitos exigidos para a implantação da Mandala. Na fase seguinte, foram entrevistados 15 produtores rurais que comercializam seus produtos na feira municipal e também o técnico responsável pelo projeto na unidade experimental da Escola Agrícola, para identificar o volume de vendas a cada feira, o preço médio dos produtos vendidos e a forma de produção adotada por estes produtores. As entrevistas foram feitas de modo informal, sem aplicação de questionário, porém com um roteiro previamente elaborado, onde foi possível a coleta dos dados necessários para proceder a análise da viabilidade e finalmente chegar à conclusão da pesquisa. Na apuração e processamento dos resultados utilizou-se da elaboração de planilhas para identificar os custos totais, a estimativa de receita com a venda dos excedentes além dos aspectos financeiros e econômicos, como indicadores que demonstrem os níveis de lucratividade e de rentabilidade oferecidos por este sistema produtivo. Ao término da pesquisa, conclui-se que o sistema de produção Mandala é uma opção viável para ser implantado em pequenas propriedades, oferece vantagens econômicas, para micro e pequenos produtores e oportuniza melhoria na qualidade alimentar para as famílias que adotam esse sistema em suas propriedades.

Palavras chaves: agricultura familiar, sustentabilidade, geração de renda.

\section{INTRODUÇÃO}

A agricultura familiar é um tema que vem sendo discutido e trabalhado em todo Brasil devido sua importância, agregado a ela, a capacidade de absorver mão de obra e a de gerar renda. Segundo dados da Assessoria de Comunicação/Ministério do Desenvolvimento Social - ASCON/MDS (2006), a maioria dos alimentos consumidos no Brasil são provenientes da agricultura familiar, e como são produzidos com menor quantidade de agrotóxicos, a procura por esses alimentos têm aumentado. Existe uma preocupação muito grande com o consumo exagerado de produtos provenientes de grandes plantações, onde se usam enormes

\footnotetext{
${ }^{1}$ Acadêmica do curso de Ciências Contábeis da UNEMAT - Campus de Tangará da Serra, kallypa.tga@terra.com.br

${ }^{2}$ Mestre em Administração (UFRN), Professora do curso de Administração da UNEMAT - Campus de Tangará da Serra, afal.lima@gmail.com
} 
quantidades de agrotóxicos na produção. Pesquisas comprovam que o consumo desses alimentos ao longo do tempo podem causar sérios danos à saúde, um exemplo disso é o câncer. Uma pesquisa realizada na cidade de Lucas do Rio Verde-MT comprovou a existência de agrotóxicos no leite materno, resultado de pesticidas e agrotóxicos borrifados por diversos anos sobre as plantações de alimentos. Segundo Palma (2010) "o estudo é uma alerta para os moradores da região, pois os resultados podem ser oriundos da exposição ocupacional, ambiental, alimentar do processo produtivo da agricultura que expôs a população a 114,37 litros de agrotóxicos por habitante na safra agrícola de 2009/2010”.

Monteiro (2009) descreve que os "compradores de legumes e verduras têm consciência da toxidade dos produtos cultivados com agrotóxicos e da dificuldade em produzí-los sem esses agrotóxicos. Essas pessoas admitem pagar entre 20 e 30\% a mais pelos produtos". Isso demonstra que as pessoas estão preferindo pagar mais caro nos alimentos produzidos com pouco ou quase nenhum tipo de agrotóxico. A ideia é gastar um pouco mais agora para economizar depois com tratamentos médicos.

A agricultura familiar tenta proporcionar a sustentabilidade, primeiramente melhores condições alimentares para os membros da família, e depois, com a comercialização dos excedentes gerar renda para os produtores.

O administrador de empresas Willy Pessoa em entrevista ao globo rural 2008, estuda maneiras de dar as famílias melhor qualidade de vida, surgiu então a ideia do programa Mandala, que busca atender as necessidades alimentares das famílias e gerar renda. O programa tem como base uma lavoura irrigada, produzindo o ano todo alimentos diversificados. Através do sistema de produção Mandala, torna-se possível cultivar verduras, legumes, frutas e ainda criar animais, tudo isso usando uma pequena área. No centro tem-se a água e logo em seguida nove anéis produtivos, inspirados no sistema solar. É possível produzir qualquer tipo de alimento no sistema de produção Mandala.

Buscando inspiração na ideia inovadora de Willy Pessoa, vendo o potencial produtivo em Tangará da Serra e avaliando os resultados obtidos com êxito em outras regiões do Brasil, é que técnicos da Secretaria Municipal de de Agricultura Pecuária e Abastecimento (SEAPA) desenvolveram uma unidade experimental do programa Mandala na Escola Agrícola Municipal Ulisses Guimarães, tendo por objetivo contribuir para o fortalecimento da agricultura familiar no município, nessa unidade experimental, a produção do sistema Mandala não é comercializada, até então só foram testados os aspectos técnicos da produção. Neste contesto o objetivo da pesquisa é identificar e calcular os custos totais, mensurar as 
possibilidades de geração de renda e apurar se o programa mandala adaptado pelos técnicos da SEAPA constitui-se de alternativa viável para as mini e pequenas propriedades rurais do município.

Em Tangará da Serra, segundo os dados do Instituto de Colonização e Reforma Agrária - INCRA (2005), são 995 propriedades rurais classificadas como mini, pequenas propriedades e pequenas propriedades produtivas de um montante de 1.335, ou seja, representam $74,53 \%$ das propriedades do município, mostrando a predominância de pequenas propriedades rurais no município.

A primeira hipótese levantada para responder ao problema foi identificar se o programa Mandala é um sistema eficiente de produção, prático e gera resultados financeiros excedentes para as pequenas propriedades rurais. A segunda hipótese levantada foi identificar se o programa Mandala não oferece ao pequeno produtor praticidade, eficiência e rentabilidade.

\title{
2 REFERECIAL TEÓRICO
}

\subsection{Agricultura Familiar}

\begin{abstract}
A agricultura familiar é uma forma de produção onde predomina a interação entre gestão e trabalho; são os agricultores familiares que dirigem o processo produtivo, dando ênfase na diversificação e utilizando o trabalho familiar, eventualmente complementado pelo trabalho assalariado. (Secretaria da Agricultura Familiar SAF, 2005).
\end{abstract}

Essa definição diz respeito a essência do trabalho familiar, onde os proprietários, ao contrário das grandes propriedades, são quem dirigem os trabalhos, fazem todo processo de produção, e eventualmente se contrata mão de obra que não seja da família.

Segundo Sznitowski (2007 p. 69) "o que comumente se pensa é que o pequeno produtor é alguém que vive em condições precárias, que tem um acesso limitado ou nulo ao sistema de crédito, trabalha com técnicas tradicionais e não consegue se integrar ao mercado mais competitivo", no entanto dizer que essas são as características essenciais da agricultura familiar é desconhecer os traços mais importantes do desenvolvimento agrícola em todos os países capitalistas avançados nos últimos anos. A agricultura familiar vem ganhando um espaço cada vez maior no mercado, gera emprego e renda.

Buainan et al (2005) consideram como agricultores familiares os que atendem a duas condições: o responsável pela direção dos trabalhos realizados na propriedade é o produtor rural e a mão de obra familiar deve ser a maioria contratada. 
Atualmente o grupo de agricultores familiares é composto em sua maioria por famílias assentadas por programas de reforma agrária. Os maiores desafios para essas famílias são organizar seu sistema de produção a partir das tecnologias disponíveis, agregar valor a sua produção e ganhar espaço no mercado. Dentro desse contesto Barros e Moraes (2006) afirmam que populações inteiras e seu imenso potencial produtivo estão sendo desperdiçados por fata de informação, organização e capacitação para o uso da água e produção de alimentos com qualidade.

Infelizmente a população de baixa renda se alimenta mal, isso quando se alimenta, muitos não tem o que comer em casa, crianças morrem por desnutrição, fome, doenças causadas pela falta de higiene, e estão enchendo os hospitais, em filas intermináveis, esperando da saúde pública uma solução que não chega. A eterna situação de miséria é resultante de riquezas e desperdícios provenientes do não aproveitamento das oportunidades produtivas locais. $\mathrm{O}$ Brasil é um país com enorme potencial produtivo, mas as oportunidades são para poucos.

No estado de Mato Grosso o fortalecimento desse setor vem sendo tema de várias discusões, através da Secretaria do Estado de Desenvolvimento Rural e Agricultura Familiar SEDRAF, que tem realizado reuniões em vários municípios do Estado, onde o objetivo é buscar fortalecimento de projetos que atendam as necessidades dos produtores que vivem da agricultura familiar, a meta principal é diminuir a importação de frutas, verduras e legumes que atualmente chega a $70 \%$ no estado, segundo dados informados pelo próprio secretário da Sedraf, José Domingos Fraga Filho que esteve no municipio de Tangará da Serra dia 12 de agosto de 2011.

\subsection{Sistemas de produção e sistema de produção Mandala}

Para Russomano (2000 p. 11) "de uma forma mais técnica, sistema de produção é um processo planejado, pelo qual elementos são transformados em produtos úteis, ou seja, um procedimento organizado para se conseguir a conversão de insumos em produtos acabados." Trata-se de uma forma de transformar matéria prima em produto acabado, praticamente tudo que utilizamos passa por algum tipo de processo de transformação, isso se chama adequar às necessidades.

No caso dos pequenos produtores pode-se citar o seguinte exemplo: os insumos são as sementes e mudas, a unidade de transformação são os sítios ou hortas e os bens ou serviços são as hortaliças e frutas ou seja o produto final.

Revista UNEMAT de Contabilidade, ano 1, n.1, jan./jun. 2012. 
Em síntese, sistema de produção é transformar algum elemento em um produto útil.

O sistema de produção Mandala tem os seguintes objetivos segundo Sebrae (2008 p. 18):

- $\quad$ Facilitar a produção de alimentos de forma sustentável;

- $\quad$ Manter a família num espaço pequeno com uma rentabilidade condicional;

- $\quad$ Produzir de forma ordenada sustentável;

- $\quad$ Redução no custo de produção;

- $\quad$ Facilidade no manejo.

O sistema de produção Mandala utiliza técnicas de manejo sustentável, como manejo integrado de pragas e doenças e manejo adequado de solo. Segundo Ramos (2010)

O manejo integrado de pragas e doenças é uma estratégia de controle múltiplo de infestações que se fundamenta no controle ecológico e nos fatores de mortalidade naturais procurando desenvolver táticas de controle que interfiram minimamente com esses fatores com o objetivo de diminuir as chances dos insetos ou doenças de se adaptarem a alguma prática defensiva em especial.

Quando a técnica do manejo integrado de pragas e doenças é bem empregada, limita os efeitos prejudiciais dos pesticidas químicos à saúde pública e ao ambiente natural. $\mathrm{O}$ objetivo não é eliminar os agentes, e sim reduzir sua população, de forma que os inimigos naturais permaneçam na plantação favorecendo o equilíbrio natural.

A adoção de certas práticas agrícolas tornam o plantio menos favorável às infestações, no caso do sistema de produção Mandala inclui rotação de culturas, seleção de áreas de plantio, uso de barreiras físicas, como valas, que dificultam a locomoção dos insetos.

A proposta é transformar a agricultura familiar em um negócio sustentável, desse modo, Pessoa (2008) em entrevista ao Globo Rural explica como surgiu a ideia de produzir alimentos em formato de Mandala:

As pessoas estão acostumadas a buscar grande quantidade de terra para plantar. Termina perdendo tempo, dinheiro e fica muito a desejar nos plantios. Então o proceso Mandala, imagem e semelhança do grande universo, e o universo são círculos desenhados concetricamente. A partir do círculo central vai ter nove círculos, que representam os planetas.

(...) a mandala é uma reprodução do nosso sistema solar, onde os planetas giram ao redor do sol. Na horta funciona assim: no centro, representando o sol, fica um reservatório de água. Ao redor dele, nove círculos. Vamos trilhar um processo modular onde, com baixo custo, você começa a produzir o primeiro círculo. Somente quando ele está produzindo, você passa para o segundo, para o terceiro, para o quarto e assim por diante até chegar no último.

O sistema de produção Mandala fuciona da seguite maneira, no centro fica um reservatório de água e uma bomba que faz a distribuição da água para os nove círculos, essa água pode vir de rios, açudes, poços e até de carro pipa. Além de irrigar os canteiros o tanque serve para criação de peixes e aves aquáticas. Nesse sistema tudo é reaproveitado, 
alimentando o pato e o marreco consequentemente os peixes tamém são alimentados. O primeiro círculo é destinado a criação de animais, que podem ser galinhas onde se aproveita a carne e os ovos, para consumo ou comércio. Destinando esse círculo para criação de animais, o processo se torna mais inteligente. Do segundo círculo em diante, o cultivo será destinado a agricultura.

Para levar a água do tanque para a plantação são utilizadas mangueiras e nelas são anexadas hastes de cotonetes ou garrafas pet perfuradas, que fazem o papel de controlar a água nas plantações. As fezes dos animais que caem no tanque de água acabam servindo de adubo para pantação. A irrigação deve ser feita de maneira uniforme. O ideal é que a família se alimente da produção dos 3 primeiros círculos e comercialize a produção dos demais círculos.

Em uma madala com nove anéis é possível a seguinte produção no decorrer de um ano:

Quadro 1 - Exemplos de possibilidades produtivas com Mandalas

Fonte: Sebrae (2008)

\begin{tabular}{|r|l|r|l|}
\hline 240 & melões & 300 & $\mathrm{~kg}$ de batata doce \\
\hline 850 & kg de abóbora & 250 & $\mathrm{~kg}$ de amendoim \\
\hline 9.000 & pés de alface & 1.000 & $\mathrm{~kg}$ de cana de açúcar \\
\hline 1.000 & cabeças de repolho & 30 & $\mathrm{~kg}$ de feijão vargem \\
\hline 360 & maços de brócolis & 150 & maços de rúcula \\
\hline 50 & kg de pimentão & 9.000 & espigas de milho verde \\
\hline 150 & kg de cebola & 300 & $\mathrm{~kg}$ de mamão \\
\hline 150 & maços de almeirão & 100 & $\mathrm{~kg}$ de maracujá \\
\hline 300 & kg de pepinos & 30 & $\mathrm{~kg}$ de figo \\
\hline 1.200 & $\mathrm{~kg}$ de bananas & 50 & $\mathrm{~kg}$ de jabuticaba \\
\hline 4.300 & maços de cheiro verde & 50 & $\mathrm{~kg}$ de chuchu \\
\hline 200 & kg de berinjela & 10 & $\mathrm{~kg}$ de acerola \\
\hline 240 & Melancias & 100 & $\mathrm{~kg}$ de limão Taiti \\
\hline 320 & $\mathrm{~kg}$ de beterraba & 5.400 & litros de leite \\
\hline 320 & kg de cenoura & 1.000 & $\mathrm{~kg}$ de frango \\
\hline 400 & kg de tomate & 1.200 & dúzias de ovos caipiras \\
\hline 1.500 & kg de mandioca & 15 & toneladas de esterco \\
\hline
\end{tabular}

Podendo ser comercializado ainda os derivados do leite, da cana de açúcar e das frutas. O exemplo acima mostra as variedades de culturas que podem ser produzidas, essas variedades ajudam no controle de pragas, que não conseguem atingir a plantação com muita intensidade, ou seja, a população desses inimigos naturais é reduzida.

Autoridades municipais e pequenos produtores que já aderiram a técnica e estão satisfeitos, a mesa fica mais colorida, mais saudável e a venda dos excedentes gera renda. 
Abaixo pode-se observar um sistema de produção em mandala.

Figura 1 - Modelo de Mandala

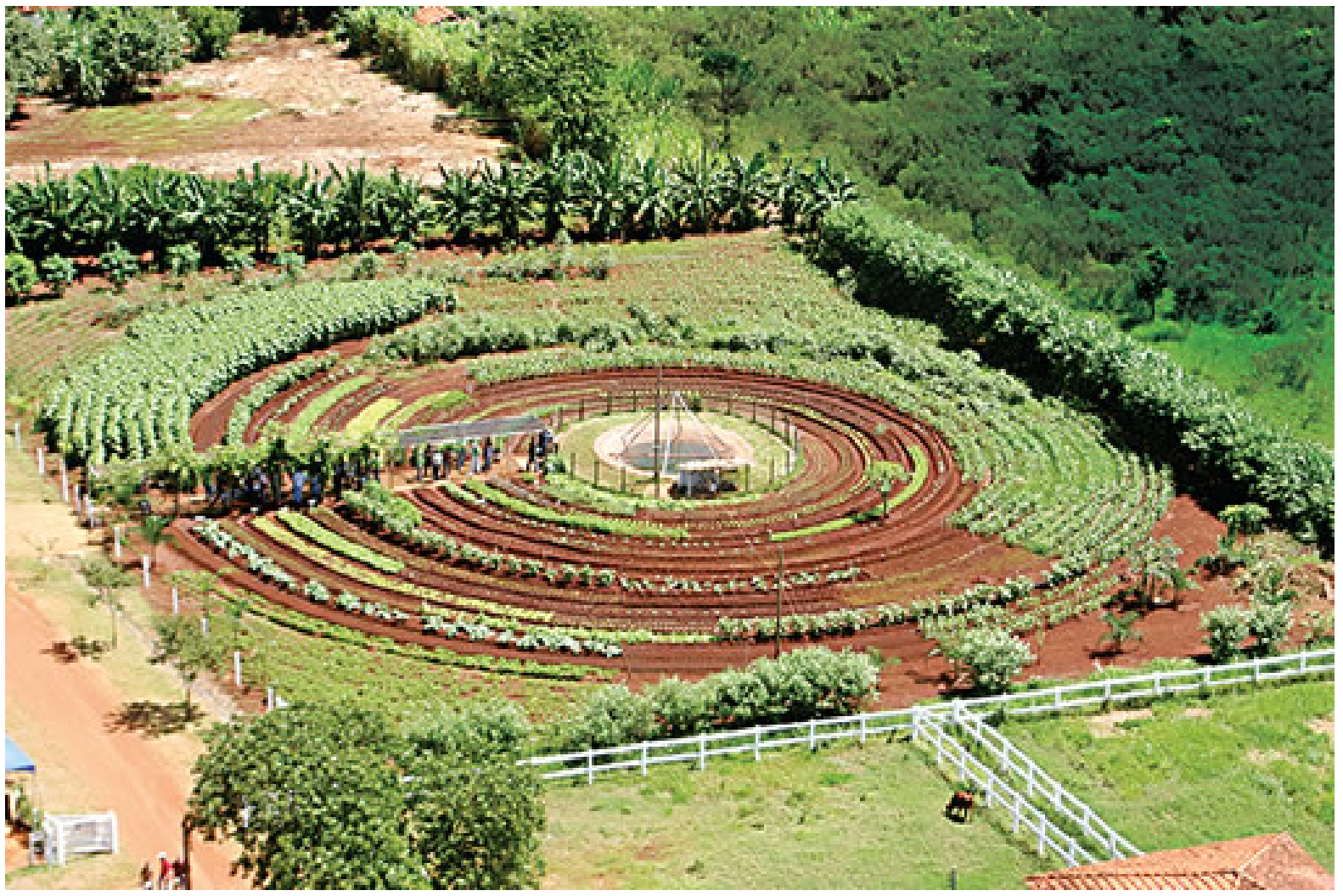

Fonte: www.espaçodosgirassois.com

Como observado na figura acima, todos os espaços devem ser aproveitados, e deve haver uma diversificação de alimentos, desde hortaliças até árvores frutíferas, bem como rotação das culturas, essa rotação e o replantio devem sempre respeitar o período de pousio da terra. (SEAPA, 2011).

\subsection{Gestão de custos}

A Gestão de Custos é um fator mais relevante para qualquer sistema produtivo, pois baseado nos custos é que as decisões são tomadas, isso garante a sobrevivência no mercado. Quem não conhece os custos de produção pode estar comercializando seus produtos a um valor não condizente, ou seja, abaixo do valor de custo, fazendo com que tenha prejuízos ou acima do preço de mercado, gerando excedentes de produção sem comercialização.

Para Perez, Oliveira e Costa (2001), além de conhecer e controlar os custos, é necessário identificar as possibilidades de melhorias de processos que resultem em identificação e eliminação de desperdícios que oneram o custo da produção e reduzem a lucratividade ou a competitividade no mercado. 
Já no custo para tomada de decisões, Perez, Oliveira e Costa (2001, p. 184) "esse sistema fundamenta-se na separação dos gastos em variáveis e fixos, isto é, em gastos que oscilam proporcionalmente ao volume da produção e vendas e gastos que se mantém estáveis perante volumes de produção e vendas oscilantes dentro de certos limites".

Essa separação é essencial na apuração dos custos totais, pois assim é possível calcular exatamente o custo.

No geral, todas os gastos no setor produtivo, são considerados custos, ou seja, são levados em consideração para esse calculo despesas para produzir, embalar, vender, comprar insumos, pagar pessoal, pagar taxas e impostos, manutenção de equipamentos, manutenção da propriedade e etc. Cita-se como exemplos na agricultura familiar as sementes, a aquisição de animais, mão de obra (mesmo que de membros da família), a energia, a água, as ferramentas, enfim, tudo é agregado ao valor do custo total.

Padoveze (2003, p. 04) conceitua custo como: "[..]mensuração econômica dos recursos (produtos, serviços e direitos) adquiridos para a obtenção e a venda dos produtos e serviços da empresa."

Megliorini (2007, p. 07) conceitua despesa como: “[...] parcela dos gastos consumida para administrar a empresa e realizar as vendas [...]”, ou seja, tudo que for gasto na administração e na comercialização do empreendimento é considerado despesa.

\subsubsection{Custos Fixos (CF) e Custos Variáveis (CV)}

São aqueles que independentemente da produção ou da comercialização acontecem na unidade produtiva. Como não tem relação com a quantidade produzida, mesmo que a produção seja de 100 unidades ou de 400, o custo fixo será o mesmo.

Segundo Serviço Brasileiro de Apoio às Micro e Pequenas Empresas - SEBRAE (2011) “custos fixos são aqueles gastos ou despesas que ocorrem mesmo que a atividade não esteja produzindo ou vendendo. Normalmente não tem relação com quantidade produzida ou vendida."

São aqueles que variam de acordo com a prdução ou a venda, ou seja, se as vendas aumentam, os custos variáveis aumentam proporcionalmente. Isso, obviamente porque quanto mais produzimos, mais temos que ter insumos para produção, e quanto mais vendemos mais temos despesas com a comercialização. Quando a produção ou as vendas caem, o custo cai proporcionalmente. 
De acordo com informações do Serviço Brasileiro de Apoio às Micro e Pequenas Empresas SEBRAE (2011) "ocorrem de acordo com a produção e a venda."

\subsubsection{Definição de gastos, investimentos e prejuízos}

A saída de dinheiro, afim de obter serviços ou produtos, pode ser entendido como custo ou despesa. Segundo Martins (1990, p. 23) gasto é: "sacrifício financeiro com que a entidade arca para a obtenção de um produto ou serviço qualquer [...]".

São aquisições feitas pela empresa registradas em seu ativo. São benefícios que o empreendedor faz, pensando no futuro, ou na vida útil de seu empreendimento.

Martins (1990, p. 24) define investimento como: "gasto ativado em função de sua vida útil ou de benefícios atribuíveis a futuro(s) período(s).

Os prejuízos simplesmente quando o total das receitas obtidas não são capazes de cobrir os custos e despesas incorridos no período, ficando um saldo negativo para o próximo período. Daí a importância de se calcular os custos e fazer previsão do preço de venda, vender os produtos por um valor que cubra os custos, essa projeção é essencial, inclusive nas unidades de produção familiares.

De acordo com Padoveze (2003, p.18) prejuízo é: “o resultado negativo de uma transação ou de um conjunto de transações [...]."

\section{METODOLOGIA}

A pesquisa é de caráter exploratório em fontes primárias (pesquisa de campo), buscou estudar, calcular e averiguar a viabilidade da implantação do programa Mandala em pequenas propriedades rurais. Foram entrevistados 15 pequenos agricultores na feira municipal, todas as entrevistas foram feitas sem aplicação de questionário, porém com um roteiro pré determinado de questionamentos, e o técnico responsável pelo projeto em Tangará da Serra. Através dessas entrevistas tornou-se possível a coleta de informações. Em fontes secundárias (pesquisa bibliográfica), onde foi feito levantamento de conceitos que trazem melhores esclarecimentos para pesquisa em livros, revistas, artigos publicados e documentos fornecidos pela própria SEAPA. Além disso foi de caráter descritivo, onde foram descritos e tabulados os dados obtidos na primeira etapa.

\section{DISCUSSÃO DE RESULTADOS}

\subsection{Unidade experimental em Tangará da Serra-MT}


Com iniciativa da SEAPA, foi implantado em 2010 no município de Tangará da Serra-MT, uma unidade experimental na Escola Agrícola Muncipal Ulisses Guimarães, com o intuito de mostar como deve ser projetada, construída e verificar a viabilidade da implantação nas pequenas propriedades rurais.

Foram feitas algumas adaptações ao projeto original. Essas adaptações devem ser feitas, pois cada propriedade terá um terreno diferente, fonte de água diferente e etc. No caso pesquisado, por exemplo, o tanque de água do centro da Mandala é maior que o recomendado no projeto original, na época da construção a escavação foi feita com trator de esteira, que não consegue fazer uma escavação pequena. A água vem canalizada de uma nascente que fica uns 400 metros próxima a Mandala. Foram utilizados pedaços de fio de cadeira no lugar das astes de cotonetes, pois são um pouco mais largos, além de aspersores convencionais no auxílio da irrigação. A utilização dos aspersores se deu porque os fios de cadeira para irrigação não funcionaram 100\%, a água da irrigação vem do tanque onde ficam os peixes, e consequentemente a sujeira que vem na água entope a saida da água pelos fios.

Como a unidade contruída na escola é experimental, e a produção não é comercializada, foram cultivados apenas 4 anéis, no projeto original são 9 assim como os planetas do sistema solar, portanto a venda dos excedentes e o lucro calculado aqui, não pode servir como regra geral. A quantidade cultivada deve ser sufuciente para suprir as necessidades alimentares o ano inteiro da família e a comercialização deve ser feita apenas dos excedentes. A unidade experimental tem as seguintes culturas em quantidade inicial, ou seja, apenas 1 colheita:

Quadro 2 - Produção do sistema mandala

Fonte: dados da pesquisa

\begin{tabular}{|l|c|c|}
\hline Produto & Quantidade & Cultura \\
\hline Abacaxi & 2215 & Permanente \\
\hline Alface & 1287 & Temporária \\
\hline Banana & 39 & Permanente \\
\hline Beterraba & 260 & Temporária \\
\hline Cebolinha & 500 & Temporária \\
\hline Cenoura & 360 & Temporária \\
\hline Coentro & 160 & Temporária \\
\hline Couve & 260 & Temporária \\
\hline Pimentão & 48 & Permanente \\
\hline Repolho & 60 & Temporária \\
\hline Rúcula & 5500 & Temporária \\
\hline Salsinha & 148 & Temporária \\
\hline Tomate & 300 & Permanente \\
\hline Galinha & 5 dúzias de ovos & Permanente \\
\hline Peixe & $115 \mathrm{~kg}$ & temporária \\
\hline
\end{tabular}


Para uma melhor compreensão, as figuras a seguir mostram a estrutura da Mandala na Escola Agrícola Municipal Ulisses Guimarães em Tangará da Serra-MT:

Figura 2 - Mandala em fase de construção

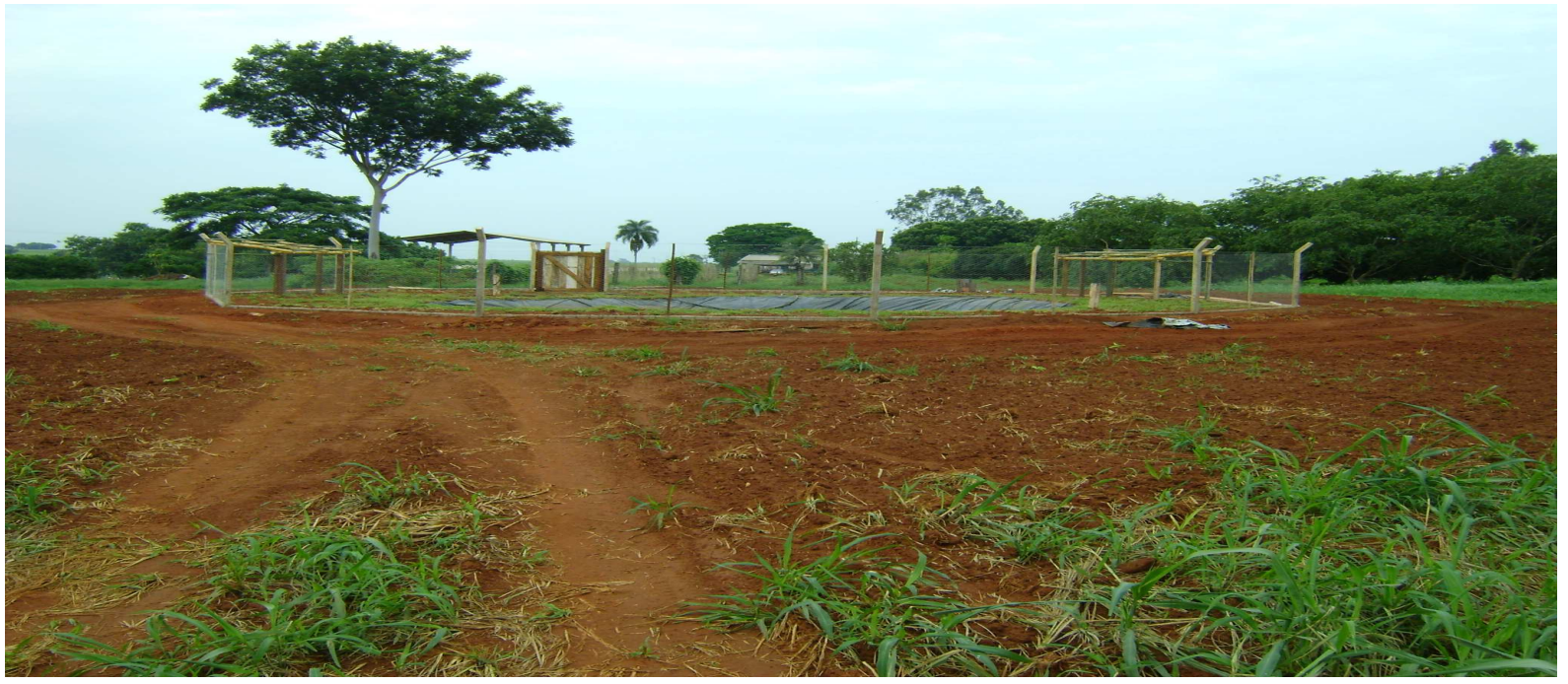

Fonte: SEAPA 2010

Foto tirada em fase de construção do galinheiro, o tanque de água já está pronto nessa fase, observa-se na figura duas casinhas para as galinhas poedeiras.

Figura 3 - Tanque para irrigação e criação de peixes

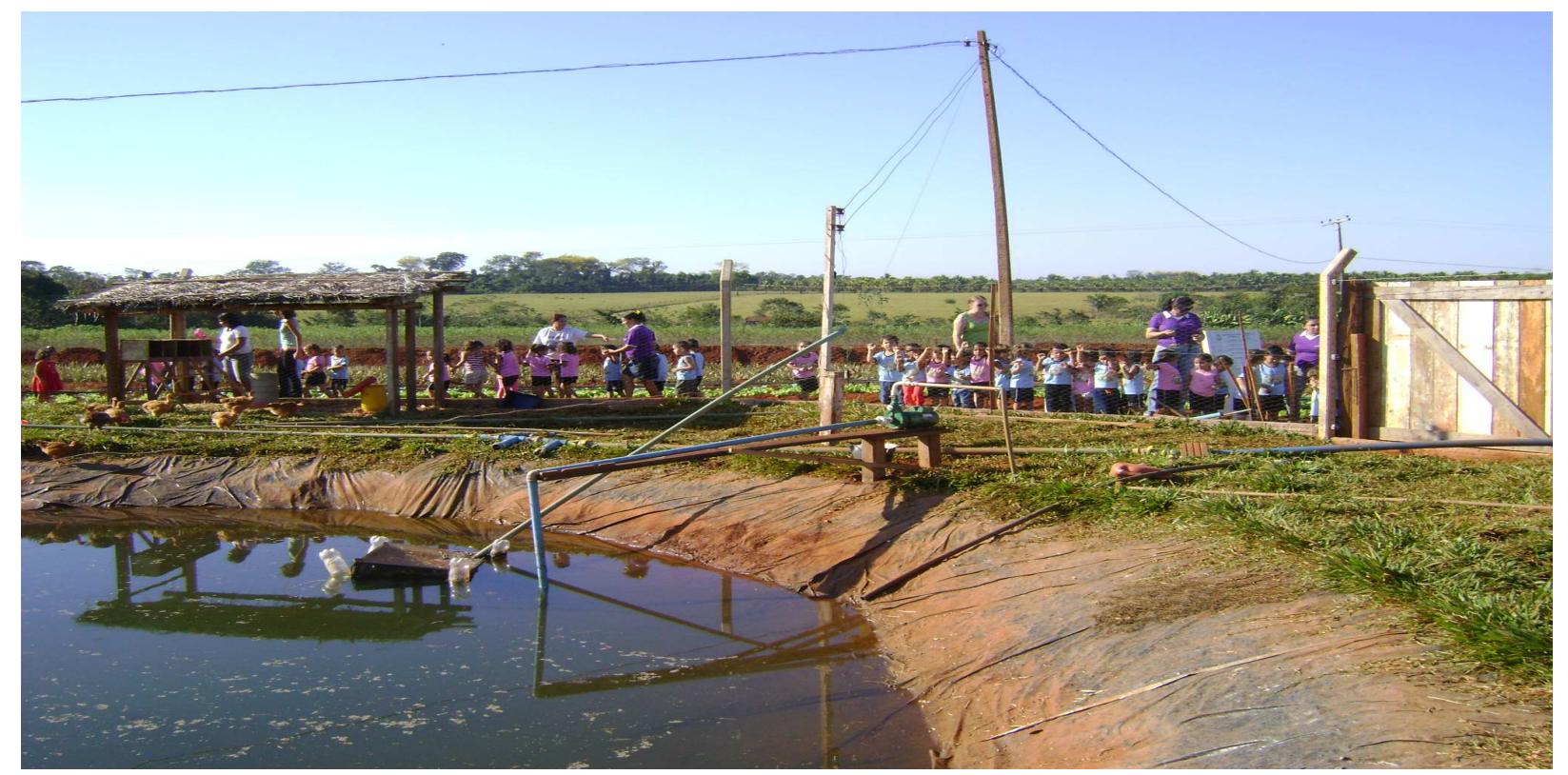

Fonte: SEAPA 2010

Crianças da APAE, em visita na inauguração da unidade.

Figura 4 - Produção Mandala

Figura 5 - Produção Mandala 


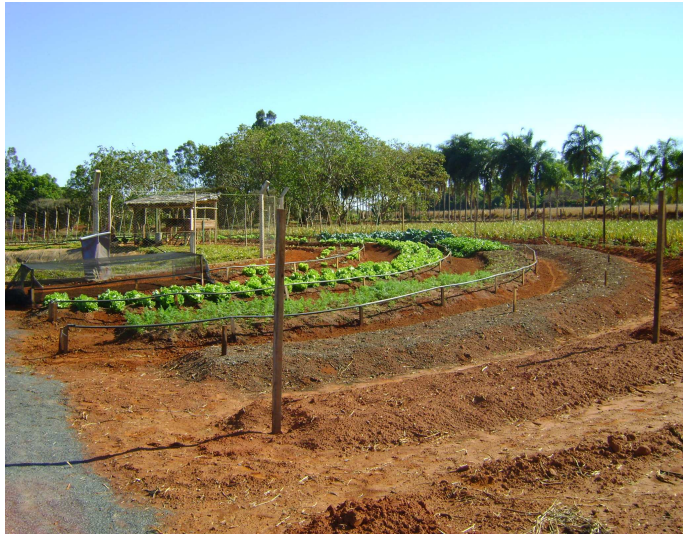

Fonte: SEAPA 2010

Figura 6 - Produção Mandala

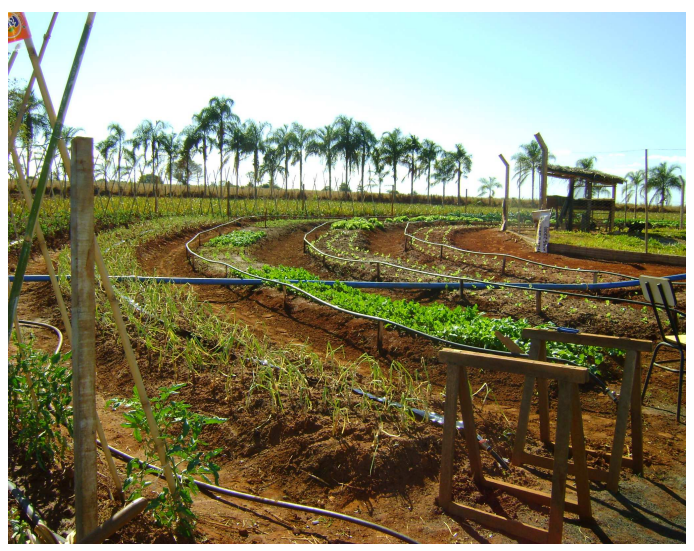

Fonte: SEAPA 2010

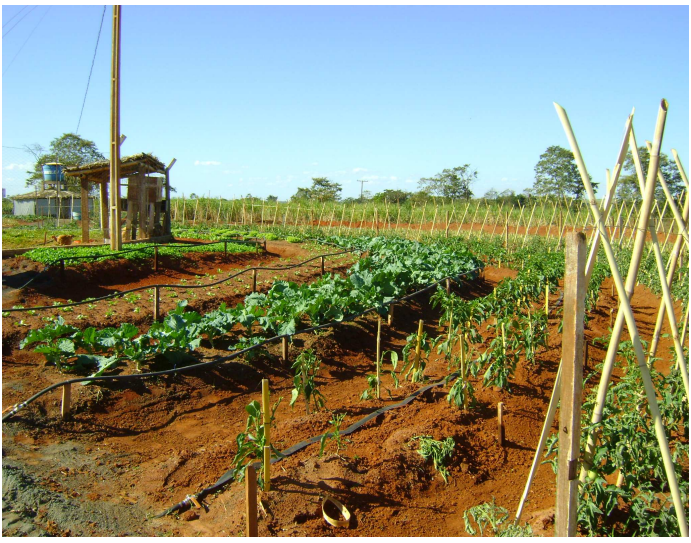

Fonte: SEAPA 2010

Figura 7 - Produção Mandala

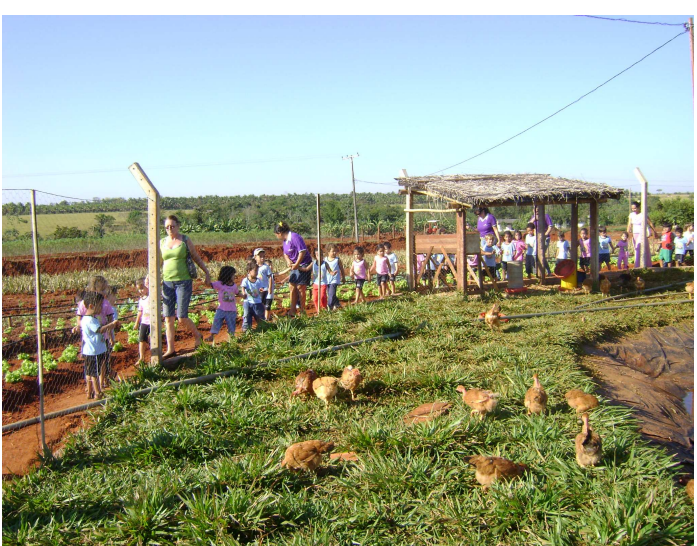

Fonte: SEAPA 2010

As figuras de 4 a 7 mostram a mandala já produzindo, inclusive a criação das galinhas. Para implantação do projeto na Escola tem-se como base os seguintes custos:

Quadro 3 - Custos de implantação do projeto Mandala

\begin{tabular}{|c|c|c|c|c|c|}
\hline Materiais & Quantidade & \multicolumn{2}{|c|}{ Valor unitário } & \multicolumn{2}{|c|}{ Valor total } \\
\hline Tela de galinheiro & $63 \mathrm{~m}$ & $\mathrm{R} \$$ & 3,00 & $\mathrm{R} \$$ & 189,00 \\
\hline M. O. construção galinheiro & 2 & $\mathrm{R} \$$ & 40,00 & $\mathrm{R} \$$ & 80,00 \\
\hline M. O. construção tanque & 2 & $\mathrm{R} \$$ & 40,00 & $\mathrm{R} \$$ & 80,00 \\
\hline Horas maquinário construção tanque & 6 & $\mathrm{R} \$$ & 180,00 & $\mathrm{R} \$$ & $1.080,00$ \\
\hline Lona plástica dupla face & $157,69 \mathrm{~m}^{2}$ & $\mathrm{R} \$$ & 1,43 & $\mathrm{R} \$$ & 225,49 \\
\hline Madeira tábuas $20 \mathrm{~cm}$ x 1,5 x 200 & $8 \mathrm{~m}$ lineares & $\mathrm{R} \$$ & 4,80 & $\mathrm{R} \$$ & 38,40 \\
\hline Madeira galinheiro - diversos pedaços & $5 \mathrm{~m}$ lineares & $\mathrm{R} \$$ & 4,80 & $\mathrm{R} \$$ & 24,00 \\
\hline Mangueira 3/4 & $330 \mathrm{~m}$ & $\mathrm{R} \$$ & 1,93 & $\mathrm{R} \$$ & 636,90 \\
\hline Registros 3/4 & 8 & $\mathrm{R} \$$ & 25,19 & $\mathrm{R} \$$ & 201,52 \\
\hline Motobomba elétrica mono $2 \mathrm{cv}-3 / 4$ & 1 & $\mathrm{R} \$$ & $1.706,82$ & $\mathrm{R} \$$ & $1.706,82$ \\
\hline Disjuntor 55A/220V & 1 & $\mathrm{R} \$$ & 51,58 & $\mathrm{R} \$$ & 51,58 \\
\hline Adaptador interno de mangueira & 16 & $\mathrm{R} \$$ & 1,53 & $\mathrm{R} \$$ & 24,48 \\
\hline Filtro de disco $3 / 4$ & 1 & $\mathrm{R} \$$ & 36,90 & $\mathrm{R} \$$ & 36,90 \\
\hline Barra/cano de água $32 \mathrm{~mm}$ & 2 barras de 6 metros & $\mathrm{R} \$$ & 17,92 & $\mathrm{R} \$$ & 35,84 \\
\hline Arame cozido & $1 \mathrm{~kg}$ & $\mathrm{R} \$$ & 6,78 & $\mathrm{R} \$$ & 6,78 \\
\hline Dobradiça portão & 2 & $\mathrm{R} \$$ & 5,09 & $\mathrm{R} \$$ & 10,18 \\
\hline Aspersores & 8 & $\mathrm{R} \$$ & 16,47 & $\mathrm{R} \$$ & 131,76 \\
\hline
\end{tabular}


Total

Fonte: dados da pesquisa

O quadro 4 apresenta os custos fixos e variáveis de produção.

Quadro 4 - Custos de produção anual

\begin{tabular}{|c|c|c|c|}
\hline Materiais/serviços & Quantidade & Valor anual & Custos \\
\hline Sementes diversas hortaliças & 240 & 480,00 & Variável \\
\hline Mudas de abacaxi & 2215 & 88,60 & Variável \\
\hline Mudas de banana & 39 & 23,40 & Variável \\
\hline Galinhas & 20 & 300,00 & Variável \\
\hline Galo & 1 & 30,00 & Variável \\
\hline Tambacu & 115 & 28,75 & Variável \\
\hline Curimba & 15 & 3,75 & Variável \\
\hline Energia elétrica & 13,12 & 157,44 & Variável \\
\hline Ração para peixes & 25,30 & 303,60 & Variável \\
\hline Mão de obra + encargos & 648,00 & $7.776,00$ & Fixo \\
\hline Total & & 9.191,54 & \\
\hline
\end{tabular}

Fonte: dados da pesquisa

$\begin{array}{lcc}\text { Custos Fixos (CF) } & \text { R\$ } & \mathbf{7 . 7 7 6 , 0 0} \\ \text { Custos Variáveis (CV) } & \text { R\$ } & \mathbf{1 . 4 1 5 , 5 4} \\ \text { Custos Totais (CT) } & \text { R\$ } & \mathbf{9 . 1 9 1 , 5 4} \\ \text { Custos mensais } & \text { R\$ } & \mathbf{7 6 5 , 9 6}\end{array}$

Para o calculo da energia foi considerado 32 horas mensais sendo 2 horas por dia, durante 4 dias da semana, a um valor de $\mathrm{R} \$ 0,41 \mathrm{kw} / \mathrm{horas}$. Ou seja $\mathrm{R} \$ 13,12$ mensais $\mathrm{x} 12$ meses $=\mathrm{R} \$ 157,44$ por ano.

A produção da Mandala e quantidade de pés na primeira colheita é a seguinte: Quadro 5 - Produção na unidade experimental

\begin{tabular}{|l|r|r|ll|l|}
\hline Produto & Quantidade plantada & $\begin{array}{l}\text { Colheitas por } \\
\text { ano }\end{array}$ & $\begin{array}{l}\text { Valor da } \\
\text { comercialização }\end{array}$ & $\begin{array}{l}\text { Forma de } \\
\text { comercializar }\end{array}$ \\
\hline Abacaxi & 2215 & 1 & $\mathrm{R} \$$ & 2,50 & Unidade \\
\hline Alface & 1287 & 1 & $\mathrm{R} \$$ & 2,00 & 4 pés em média \\
\hline Banana & 39 & 3 & $\mathrm{R} \$$ & 2,50 & $\mathrm{Kg}$ \\
\hline Beterraba & 260 & 12 & $\mathrm{R} \$$ & 2,00 & Maço \\
\hline Cebolinha & 500 & 3 & $\mathrm{R} \$$ & 1,00 & Maço \\
\hline Cenoura & 360 & 12 & $\mathrm{R} \$$ & 2,00 & Maço \\
\hline Coentro & 160 & 6 & $\mathrm{R} \$$ & 1,00 & Maço \\
\hline Couve & 1560 & 2 & $\mathrm{R} \$$ & 1,50 & Maço \\
\hline Pimentão & 48 & durante 4 meses & $\mathrm{R} \$$ & 6,00 & Kg \\
\hline Repolho & 60 & 8 & $\mathrm{R} \$$ & 1,75 & Cabeça \\
\hline Rúcula & 5500 & 12 & $\mathrm{R} \$$ & 1,50 & Maço \\
\hline Salsinha & 148 & 1 & $\mathrm{R} \$$ & 1,00 & Maço \\
\hline Tomate & 300 & durante 2 meses & $\mathrm{R} \$$ & 2,50 & Kg \\
\hline Peixe & 115 & 12 & $\mathrm{R} \$$ & 8,00 & Kg \\
\hline Ovos & 20 & & 3,00 & Dúzia \\
\hline
\end{tabular}

Fonte: dados da pesquisa 
Simulando-se as vendas e levando em consideração que $30 \%$ da produção é para consumo da família, e, ainda que $20 \%$ deve ser considerado como perdas devido a fatores inevitáveis como as chuvas por exemplo. Considera-se portanto a venda de $50 \%$ da sua produção para geração de renda da família.

Quadro 6 - Valor dos excedentes vendidos

Fonte: dados da pesquisa

\begin{tabular}{|l|r|r|}
\hline Produto & $\mathbf{R} \$$ anual & $\mathbf{5 0 \%}$ \\
\hline Abacaxi & $\mathrm{R} \$ 5.537,50$ & $\mathrm{R} \$ 2.768,75$ \\
\hline Alface & $\mathrm{R} \$ 1.930,50$ & $\mathrm{R} \$ 965,25$ \\
\hline Banana & $\mathrm{R} \$ 3.510,00$ & $\mathrm{R} \$ 1.755,00$ \\
\hline Beterraba & $\mathrm{R} \$ 222,00$ & $\mathrm{R} \$ 111,00$ \\
\hline Cebolinha & $\mathrm{R} \$ 1.500,00$ & $\mathrm{R} \$ 750,00$ \\
\hline Cenoura & $\mathrm{R} \$ 310,00$ & $\mathrm{R} \$ 155,00$ \\
\hline Coentro & $\mathrm{R} \$ 275,00$ & $\mathrm{R} \$ 137,50$ \\
\hline Couve & $\mathrm{R} \$ 4.180,00$ & $\mathrm{R} \$ 2.090,00$ \\
\hline Pimentão & $\mathrm{R} \$ 1.440,00$ & $\mathrm{R} \$ 720,00$ \\
\hline Repolho & $\mathrm{R} \$ 315,00$ & $\mathrm{R} \$ 157,50$ \\
\hline Rúcula & $\mathrm{R} \$ 4.950,00$ & $\mathrm{R} \$ 2.475,00$ \\
\hline Salsinha & $\mathrm{R} \$ 253,00$ & $\mathrm{R} \$ 126,50$ \\
\hline Tomate & $\mathrm{R} \$ 12.000,00$ & $\mathrm{R} \$ 6.000,00$ \\
\hline Peixe & $\mathrm{R} \$ 920,00$ & $\mathrm{R} \$ 460,00$ \\
\hline Ovos & $\mathrm{R} \$ 150,00$ & $\mathrm{R} \$ 75,00$ \\
\hline total anual & $\mathbf{R} \$ \mathbf{3 7 . 4 9 3 , 0 0}$ & $\mathbf{R} \mathbf{1 8 . 7 4 6 , 5 0}$ \\
\hline total mensal & & $\mathbf{R} \$ \mathbf{1 . 5 6 2 , 2 1}$ \\
\hline
\end{tabular}

Para o pequeno produtor o faturamento mensal seria de $\mathrm{R} \$ 1.562,21$ com a venda de $50 \%$ de sua produção total anual, menos os custos de manutenção $\mathrm{R} \$ 765,96$ o lucro líquido é de R \$796,25 mensais conforme Demosntração do Resultado do Exercício (DRE) abaixo.

Quadro 7 - Demonstração do resultado do exercício (DRE)

\begin{tabular}{|l|l|}
\hline Receita Operacional Bruta & $37.493,00$ \\
\hline (-) Perdas e Consumo & $-18.746,50$ \\
\hline (=) Receita Operacional Bruta & $18.746,50$ \\
\hline (-) Custos de Produção & $-9.191,54$ \\
\hline (=) Resultado Líquido do Exercício & $\mathbf{9 . 5 5 4 , 9 6}$ \\
\hline
\end{tabular}

Fonte: dados da pesquisa

Através dessas demosntrações acima, chega-se ao calculo do índice de lucratividade e rentabilidade:

Lucratividade $=\underline{\text { Lucro líquido }} \times 100$

Faturamento

Lucratividade $=\underline{9.554,96} \times 100$ 


\section{$18.746,50$}

\section{Lucratividade $=\mathbf{5 0 , 9 6 \%}$}

Esse indicador demonstra em percentual qual o ganho que o negócio consegue ter sobre suas vendas.

Rentabilidade do período $=\underline{\text { Lucro líquido }} \times 100$

Investimento total

Rentabilidade do período $=\underline{9.554,96} \times 100$

$$
4.559,65
$$

Rentabilidade do período $=\mathbf{2 0 9 , 5 5 \%}$

Rentabilidade mensal $=\underline{\text { Rentabilidade do período }}$

12 meses

\section{Rentabilidade mensal $=17,46 \%$}

Isso significa que de todo valor investido pelo produtor, 17,46\% retorna em 1 mês sob forma de lucro. Ou seja, em menos de 6 meses tem-se o retorno do investimento inicial.

\section{CONSIDERAÇÕES FINAIS}

Conforme demonstrado na dicussão dos resultados apurados, a produção em Mandala mostra-se um negócio lucrativo e sustentável, primeiramente a família consegue ter uma alimentação mais saudável e depois vem a geração de renda com a venda dos excedentes de seu sistema produtivo.

Como na unidade experimental analisada não foram utilizados todos os anéis produtivos, existe a possibilidade de uma família que utiliza o sistema produtivo com total aproveitamento da área útil disponível e que respeita o período de pousio da terra lucrar muito mais.

O problema levantado que era identificar se o programa Mandala é uma alternativa financeiramente viável para os mini e pequenos produtores rurais de Tangará da Serra-MT foi respondido positivamente e a hipótese atendida. Ressalta-se ainda a importância do resgate cultural nas famílias, atualmente muitas crianças não sabem de onde vem os alimentos, pensam que os alimentos nascem nas bancas de supermercado. Com o incentivo da produção familiar, as crianças acompanham todo o processo produtivo, aprendem sobre os alimentos e a importância deles. 


\section{REFERÊNCIAS BIBLIOGRÁFICAS}

Assessoria de Comunicação/Ministério do Desenvolvimento Social - ASCON/MDS. 2206. Disponível em http://www.oibescoop.org/media/bank/novos_paradigmas.pdf acesso em 12 de agosto de 2011.

BARROS, Fernanda; MORAES, Vanda. Projeto Mandalla. Disponível em:

<http://agriculturacomunitaria.blogspot.com/.> Acesso em 07 de maio de 2011.

BOTH, Sérgio José; SIQUEIRA, Claudineide Julião de Souza. Metodologia cientifica faça fácil a sua pesquisa. Tangará da Serra, MT: Editora São Francisco, 2004.

BUAINAIN. Antônio Márcio et al. Peculiaridades da agricultura familiar brasileira. In: SOUZA FILHO, Hildo Meirelles; BATALHA, Mário Otávio. Gestão integrada da agricultura familiar. São Carlos: Edusfcar, 2005.

FERNANDES, Ângela Esther Borges Fernandes. O perfil da agricultura familiar brasileira. Disponível em < http://www.webartigos.com/articles/16496/1/O-PERFIL-DA-AGRICULTURAFAMILIAR-BRASILEIRA/página1.html\#ixzz1LTTpF1Gka.> Acesso em 05 de maio de 2011.

GIL, Antonio Carlos. Como elaborar projetos de pesquisa. 4 ed. São Paulo: Atlas, 2002 e 2008.

Globo Rural. Projeto mandala, sistema de canteiros concêntricos formados ao redor de fonte d'água, gera trabalho e renda no sertão paraibano, ajudando a reativar a economia. Disponível em <http://revistagloborural.globo.com/globorural/0,6993, EEC738707-1641,00.html > acesso em 05 de maio de 2011.

Instituto Nacional de Colonização e Reforma Agrária - INCRA, 2005.

MONTEIRO, Kelly. Orgânicos: prazer e responsabilidade em consumir <http://www.vitaplena.com.br/organico/organicos-prazer-e-responsabilidade-em-consumir $>$

LAKATOS, E. M., MARCONI, M. de A. Fundamentos de metodologia científica. 3. Ed. São Paulo: Atlas, 1991.

Lei da Agricultura Familiar. Sancionada em Brasília. Disponível em http://www.fomezero.gov.br/noticias/sancionada-em-brasilia-lei-da-agricultura-familiar sancionada em 25/07/2006 acesso em 30 de agosto de 2011.

MARTINS, Eliseu. Contabilidade de Custos. Ed. 4. São Paulo: Atlas, 1990.

MEGLIORINI, Evandir. Custos: Análise e Gestão. 2. Ed. São Paulo: Pearson Prentice Hall, 2007.

MONTEIRO, Kelly. Orgânicos: prazer-e-responsabilidade-em-consumir. Disponível em http://www.vitaplena.com.br/organico/organicos-prazer-e-responsabilidade-em-consumir> Acesso em 30 de agosto de 2011.

NÉRI, Priscila. Irrigação alternativa melhora renda no campo. Disponível em $<$ http://pib.socioambiental.org/es/noticias?id=35804. $>$ Acesso em 11 de maio de 2011.

PADOVEZE, Clóvis Luís. Curso Básico Gerencial de Custos: Para cursos de Administração de Empresas, Economia e Engenharia. São Paulo: Pioneira Thomson Learning, 2003. 
PALMA, Danielly. Agrotóxico encontrado no leite materno. Dispoível em $<$ http://luznocaminho.net/2011/08/01/agrotoxico-encontrado-no-leite-materno > Instituto Ethos. Acesso em 30 de agosto de 2011.

PEREZ JR., José Hernandes; OLIVEIRA, Luís Martins de; COSTA, Rogério Guedes. Gestão estratégica de custos. 2 ed. São Paulo: Editora Atlas S.A., 2001.

PORTUGAL, Alberto Duque. O desafio da agricultura Familiar. Disponível em <http://www.embrapa.br/imprensa/artigos/2002/artigo.2004-12-07.2590963189/. > Acesso em 05de maio de 2011.

Prefeitura Municipal de Tangará da Serra. http://www.tangaradaserra.mt.gov.br/noticia.asp?codigo=6482 Acesso em 12 de agosto de 2011.

PRIA, Anna Dalla. Projeto Mandalla e os benefícios que estão fazendo na Paraíba e no Brasil. Disponível em <http://www.agenciamandalla.org.br/modules.php?name=New\&file=print\&sid=91. $>$ Acesso em 19 de abril de 2011.

PROGRAMA NACIONAL DE FORTALECIMENTO DA AGRICULTURA FAMILIAR PRONAF. Pronaf. Disponível em:

<http://www.bnb.gov.br/content/aplicacao/Pronaf/Grupos_e_linhas/gerados/gb_grupos_txt.asp?idTR= pronaf.> Acesso em 19 de abril de 2011.

QUADRADO, Adriano. Vida Simples. Disponível em

$<$ http://vidasimples.abril.com.br/subhomes/comer/comer_238175.shtml?pagina=0> Acesso em 30 de agosto de 2011.

RAMOS, Mariana. Manejo Integrado de Pragas, Controlando pragas e cuidando do meio ambiente. Disponível em

$<$ http://www.wwf.org.br/natureza_brasileira/reducao_de_impactos2/agricultura/agr_acoes_res ultados/controlando_pragas_de_maneira_ambientalmente_correta> Acesso em 30 de agosto de 2011.

RIBEIRO, Magno Alves; TORRES, Ariel Lopes; ROCHA, Margarida Alves. Manual para elaboração e apresentação de monografias. Com Noções Introdutórias de Metodologia. 1. Ed. Tangará da Serra: Editora Sanches, 2006.

ROCHA, Cerena. Mandala na agricultura sustentável. Disponível em: http://espaçodosgirassois.blogspot.com/2011/05/mandala-na-agricultura-sustentável.html. Acesso em 25 de maio de 2011.

RUSSOMANO, Victor Henrrique. Planejamento e Controle da Produção. 6 ed. São Paulo: Editora Pioneira, 2000.

SAF. Portal da Agricultura Familiar. Perguntas e Respostas. Disponível em:

<http://www.mda.gov.br/saf/index.php?sccid=1243.> Acesso em 07 de maio de 2011.

SEBRAE. Revolução silenciosa, agricultura ecológica e integrada traz desenvolvimento social sustentável para as famílias do campo. Revista $\mathrm{n}^{\circ} 7$, dezembro 2007.

SEBRAE. Inovação no campo, pequenos negócios rurais apostam na diferenciação para ampliar competitividade. Revista $n^{\circ} 8$, abril, 2008.

Secretaria de Agricultura e Meio Ambiente/Empaer/Assoc dos Eng. Agrônomos. Estrutura

Agropecuária. Disponível em <http://www.tangaradaserra.mt.gov.br/economia/agripec.asp. $>$ Acesso em 12 de maio de 2011. 
SEVERINO, Antônio Joaquim. Metodologia do trabalho cientifico. 22 ed. São Paulo:Cortez, 2002.

SZNITOWSKI, Adelice Minetto. Fatores que podem contribuir para a ocorrência de acidentes de trabalho pelo uso de agrotóxicos entre os agricultores familiares no assentamento guapirama em Campo Novo do Parecis-MT. Edição. São Carlos: Editora UFSCAR, 2010. 